\title{
Lung function and asthma control in school-age children managed in UK primary care: a cohort study
}

\author{
David KH Lo (1) , 1,2 Caroline S Beardsmore, ${ }^{3}$ Damian Roland, ${ }^{4,5}$ Mathew Richardson, ${ }^{6,7}$ \\ Yaling Yang ${ }^{8}$ Lesley Danvers, ${ }^{2}$ Andrew Wilson, ${ }^{9}$ Erol A Gaillard ${ }^{2,3}$
}

For numbered affiliations see end of article.

\section{Correspondence to}

Dr Erol A Gaillard, Department of Respiratory Sciences. Leicester NIHR Biomedical Research Centre (Respiratory theme), University of Leicester, Leicester LE2 7LX, UK : eag15@le.ac.uk

Received 9 January 2019 Revised 22 August 2019 Accepted 23 September 2019 Published Online First 30 October 2019

\section{SLinked}

- http://dx.doi.org/10.1136/ thoraxjnl-2019-214143

Check for updates

(C) Author(s) (or their employer(s)) 2020. No commercial re-use. See rights and permissions. Published by BMJ.

To cite: Lo DKH

Beardsmore CS, Roland D,

et al. Thorax

2020;75:101-107

\section{ABSTRACT}

Background Spirometry and fraction of exhaled nitric oxide (FeNO) are commonly used in specialist centres to monitor children with asthma. The National Institute for Health and Care Excellence recommends spirometry for asthma monitoring from 5 years in all healthcare settings. There is little spirometry and FeNO data in children managed for asthma in UK primary care to support their use.

Objectives To study the prevalence of abnormal spirometry and FeNO in children with asthma managed in primary care and to explore their relationship with asthma control and unplanned healthcare attendances (UHA).

Methods Prospective observational cohort study in children aged 5-16 years with suspected or doctordiagnosed asthma attending an asthma review in UK general practice. Spirometry, FeNO, asthma control test (ACT) scores and number of UHAs were studied. Results of 612 children from 10 general practices, $23.5 \%$ had abnormal spirometry, $36.0 \%$ had raised FeNO $\geq 35$ parts per billion and $41.8 \%$ reported poor control. Fifty-four per cent of children reporting good asthma control had abnormal spirometry and/or raised FeNO. At follow-up, the mean number of UHAs fell from $0.31 /$ child in the 6 months preceding review to 0.20 / child over the 6 months following review $(p=0.0004)$. Median ACT scores improved from 20 to 22 ( $p=0.032$ ), and children's ACT from 21 to $23(p<0.0001)$. Conclusions Abnormal lung function and FeNO are common in children attending for asthma review in primary care and relate poorly to symptom scores. A symptoms-based approach to asthma monitoring without objective testing is likely to miss children at high risk of future severe asthma attacks.

\section{INTRODUCTION}

The UK has one of the highest asthma mortality rates among high-income countries in Europe in young people aged $10-24$ years. ${ }^{1}$

The existing UK British Thoracic Society/Scottish Intercollegiate Network Guideline defines good asthma control in terms of current symptoms control' ${ }^{2}$; recommending that 'asthma is best monitored in primary care by routine clinical review', using standardised questionnaires but do not promote the need for objective lung function testing. This is in contrast with recommendations from the Global Initiative for Asthma (GINA), which divides assessment of asthma control into two domains: 1) evaluation of current symptom

\section{Key messages}

What is the key question?

- How common is abnormal spirometry and fraction of exhaled nitric oxide (FeNO) in children managed for asthma in primary care, and what is their relationship with patientreported asthma control?

What is the bottom line?

- Abnormal spirometry and FeNO are prevalent in children cared for in primary care, and a symptoms-based asthma assessment alone will under-recognise children with obstructed airflow or active airway inflammation.

Why read on?

- To our knowledge, this is the first primary care study to explore the role of spirometry and FeNO testing in children managed for asthma in the UK.

control and 2) identifying risk factors for future poor outcomes, which include poor lung function.

The importance of assessing future asthma risk was also highlighted in the 2014 UK National Review of Asthma Deaths. This report found that the severity of asthma was underestimated in twothirds of children who died from asthma between 2012 and 2013, ${ }^{3}$ and identified deficiencies in the recognition of patients at high risk of asthma attacks and death. One of the key recommendations from the report was that 'practices need to adopt a system of establishing the risk profile of a patient and put a treatment plan in place that is appropriate to their risk profile'.

GINA recommends that spirometry is recognised as an important part of the assessment of future asthma risk, ${ }^{4}$ and more recently the UK National Institute for Health and Care Excellence (NICE) published asthma guidelines ${ }^{5}$ recommending the use of spirometry for asthma monitoring in children aged 5 years and over.

The role of fraction of exhaled nitric oxide (FeNO) monitoring is less clear, although there is some evidence to suggest that FeNO-guided asthma treatment reduces exacerbation rates in children when compared with guidelines-based asthma management. ${ }^{6}$ GINA lists raised FeNO as a risk factor for future asthma attacks, at least in adults, while NICE recommends consideration of FeNO measurements to support asthma management in 
people who are symptomatic despite using inhaled corticosteroids. In primary care, spirometry and FeNO are rarely measured in the management of asthma in children or adults.

Implementation of spirometry and FeNO monitoring would represent a major change in routine primary care asthma management and has understandably raised concerns among stakeholders. $^{7-9}$ This is chiefly because there is little UK data relating to lung function and asthma control in children managed in primary care.

We conducted a pragmatic prospective observational study in primary care with the objectives to quantify: 1 ) the prevalence of abnormal spirometry, $\mathrm{FeNO}$ and poor current asthma control at a single time-point in a cohort of children with either suspected or an existing diagnosis of asthma, and 2) the proportion of children in whom an assessment based on current symptoms alone would have failed to identify those with abnormal lung function and $\mathrm{FeNO}$ who may be at an increased risk of a severe asthma attack. As a secondary outcome, we explored the change in current asthma control and the number of unplanned healthcare attendances (UHAs) in the 6 months following a structured clinical review that included spirometry and FeNO testing.

\section{METHODS}

Prospective observational cohort study in children managed in primary care in the East Midlands, UK between 2016 and 2017.

\section{Practices}

Identification of general practices was facilitated by the Clinical Research Network. We sought to include practices of different sizes, serving populations of different ethnic and socioeconomic profiles. Seventeen general practices were contacted and 10 expressed an interest to participate.

\section{Participants}

Children aged 5-16 years with an existing asthma diagnosis or children receiving asthma medications (suspected asthma) were eligible to participate. Children fulfilled the inclusion criteria if at least one of the following was present:

1. On the practice asthma register.

2. Prescribed inhaled corticosteroids within the previous 12 months.

3. Prescribed $\geq 2$ short acting beta-2-agonist via metered dose inhalers (SABA MDIs) in the previous 12 months.

4. Prescribed oral corticosteroids for acute wheeze/cough/ breathlessness in the previous 12 months.

Eligible children were identified from the electronic register of each participating practice and invited by letter to attend the practice for an asthma review. Families who did not respond to the first letter were sent a second invitation and/or contacted by telephone by their registered practice.

\section{Procedures}

Training in performing and interpreting spirometry and FeNO was provided for clinical staff at each practice by the research team.

Clinical staff were trained to review and adjust treatment plans, and adherence to asthma preventer medications, of any child with either poor symptom control or abnormal objective test results. As all clinical reviews were conducted by the practice staff independent of the research team, the routine checking of inhaler technique and issuing of written personalised asthma action plans at each clinical review was encouraged but not monitored as part of this study.
Written consent was sought from all families attending for an asthma review for the purposes of data collection. Spirometry and FeNO testing were attempted in all children.

\section{Asthma control tests}

Validated questionnaires were used to assess current asthma control; the asthma control test (ACT) ${ }^{10}$ for children aged $\geq 12$ years, and the childhood asthma control test $(\mathrm{CACT})^{11}$ for children aged 5-11 years. A score of $\leq 19$ in either questionnaire denotes current uncontrolled asthma, with better control indicated by higher values. ${ }^{5}$

\section{Spirometry}

Spirometry was performed using a portable spirometer (CareFusion, UK) by practice staff either directly supervised or independently once competent. Forced expiratory manoeuvres were performed according to American Thoracic Society and European Respiratory Society (ATS/ERS) standards. ${ }^{12}$

Predicted values were based on global lung initiative (GLI) reference equations. ${ }^{13}$

For training purposes, a normal spirogram was defined as having both $\mathrm{FEV}_{1}$ and $\mathrm{FVC} \geq 80 \%$ predicted and $\mathrm{FEV}_{1} / \mathrm{FVC}$ $\geq 80 \%$. A fixed cut-off was chosen to define obstruction for pragmatic reasons, as it was felt that general practice staff were already familiar with using fixed cut-offs when interpreting adult spirometry. The $80 \%$ threshold was chosen as it most closely mirrors the GLI lower limits of normal (LLN) across the 5-16 years age group.

Where $\mathrm{FEV}_{1}$ or $\mathrm{FVC}$ was $<80 \%$ predicted, or $\mathrm{FEV}_{1} / \mathrm{FVC}$ $<80 \%$, reversibility testing was performed: after administering salbutamol $400 \mu \mathrm{g}$ via spacer. An increase in absolute $\mathrm{FEV}_{1}(\mathrm{~L})$ of $\geq 12 \%$ was taken to represent a positive bronchodilator response (BDR) test.

\section{Fraction of exhaled nitric oxide}

FeNO measurements were attempted in all children following spirometry and performed in accordance with standardised guidelines. ${ }^{14}$ We used a handheld FeNO analyser (NIOX Vero; Circassia). We used a cut-off value of $\geq 35$ parts per billion (ppb) to represent evidence of current active airway inflammation. ${ }^{5}$

\section{Follow up}

We reviewed each participant's electronic records 6 months following the initial asthma review. All record entries including consultations, electronically filed letters and prescriptions for the 6 months period were reviewed in order to obtain the number of UHA since the initial review. A UHA was defined as any attendance to the GP, hospital or walk-in centre with acute respiratory symptoms managed with asthma medications as documented within GP records or filed as an electronic discharge letter from hospital. In patients who consented, we also sent out follow-up letters with repeat ACT/CACT questionnaires.

\section{Data analysis}

We compared baseline characteristics, lung function test results and UHAs between children who were on the practice asthma register with those who were not. Continuous variables were compared using unpaired t-tests for parametric data, and KruskalWallis and Wilcoxon signed rank tests for non-parametric data. Chi-squared tests were used for count data.

Lung function data were analysed according to the diagnostic status, age group and the current asthma symptom control status of the children, as binary variables. We used a fixed cut-off for 
$\mathrm{FEV}_{1}$ predicted and $\mathrm{FEV}_{1} / \mathrm{FVC}$ of $80 \%$ to define airflow obstruction for training purposes. However for analysis, the gold standard GLI LLN were used.

Potential correlations between lung function parameters and ACT/CACT scores were tested using Pearson's $r$ correlation for parametric variables and Spearman's rank for ordinal or non-parametric data. The above analyses were performed after converting spirometric parameters into z-scores using GLI software.

Paired t-tests and Wilcoxon signed rank tests were used to assess the change in ACT/CACT scores and number of UHAs in children at follow-up. Statistical analyses were performed using IBM SPSS Statistics for Windows (V.24.0, IBM, Armonk, New York, USA) and GraphPad Prism V.7.00 for Windows (GraphPad Software, USA, www.graphpad.com). All statistical tests were performed at $\alpha=5 \%$ level.

\section{RESULTS}

\section{Participating practices}

Ten practices participated in this study. They served a population of almost 120000 people, ranging from $\sim 3500$ to 48000 registered patients. Geographically, five of the practices were located in inner-city Leicester, three were in surrounding towns and two were in village locations.

\section{Participants}

Electronic database searches identified 1548 eligible children: 1097 (71\%) were on their GPs asthma register and 451 (29\%) were not, but had received asthma medications in the previous 12 months.

In total, 614 children responded to the written invitations and attended clinics held between June 2016 and August 2017; of these, $456(75 \%)$ were on the asthma register. Sixty-three per cent of children were recruited in the months of March to August, and the remainder in the months of September to February.

Written informed consent was obtained from carers of 613 children. One parent refused consent and one parent later withdrew their consent without giving a reason, leaving 612 children in total. The characteristics of recruited children are shown in table 1 . Overall, the participation rate was $40 \%$ of eligible patients, but ranged from $8 \%$ to $59 \%$ between practices. The practice recruiting only $8 \%$ of eligible children was an outlier, and due in part to recruitment at this practice commencing late into the study and therefore fewer clinics (in relation to the practice size) were set up compared with other practices.

\section{Baseline spirometry, FeNO and asthma control test data Spirometry}

Acceptable spirometry was achieved by 575 (94.0\%) children.

Using the definition $\mathrm{FEV}_{1}$ or $\mathrm{FEV}_{1} / \mathrm{FVC}<\mathrm{LLN}, 135$ out of 575 $(23.5 \%)$ children had airflow obstruction. There was no difference in the prevalence of obstructed spirometry between children with diagnosed asthma versus those without a confirmed diagnosis, $23.7 \%$ vs $23.4 \%(\mathrm{p}=0.95)$.

For comparison, the numbers of children defined as having airflow obstruction according to different thresholds are presented in table 2. Compared with using GLI LLN, using a fixed cut-off of $\mathrm{FEV}_{1}<80 \%$ predicted or $\mathrm{FEV}_{1} / \mathrm{FVC}<80 \%$ misidentified an additional $37(6 \%)$ children as having airflow obstruction, but using the NICE recommended cut-off of $\mathrm{FEV}_{1}$ / FVC $<70 \%$ would have missed airflow obstruction in 108 (18\%) children.
Table 1 Baseline characteristics of recruited children

\begin{tabular}{|c|c|c|c|}
\hline & $\begin{array}{l}\text { On asthma } \\
\text { register }(n=456)\end{array}$ & $\begin{array}{l}\text { Not on asthma } \\
\text { register }(n=156)\end{array}$ & $P$ value \\
\hline No. of males (\%) & $247(54.2)$ & $85(54.5)$ & 0.945 \\
\hline Mean age in years (SEM) & $10.3(0.15)$ & $9.1(0.26)$ & $<0.001^{*}$ \\
\hline $\begin{array}{l}\text { No. of children with previous } \\
\text { spirometry testing (\%) }\end{array}$ & $53(11.7)$ & $5(3.2)$ & $0.002^{*}$ \\
\hline $\begin{array}{l}\text { Total daily prescribed dose } \\
\text { (beclomethasone equivalent) } \\
\text { of inhaled corticosteroids in } \\
\text { micrograms (SEM) }\end{array}$ & $227.41(10.47)$ & $87.18(12.32)$ & $<0.001 *$ \\
\hline $\begin{array}{l}\text { Mean number of UHAs per } \\
\text { child in preceding } 6 \text { months } \\
\text { (SEM) }\end{array}$ & $0.29(0.03)$ & $0.37(0.06)$ & 0.175 \\
\hline $\begin{array}{l}\text { Number of children with } \geq 1 \\
\text { UHA in preceding } 6 \text { months } \\
\text { (\%) }\end{array}$ & $98(21.5)$ & $42(26.9)$ & 0.163 \\
\hline Mean $\mathrm{FEV}_{1} \%$ predicted (SEM) & $93.29(0.64)$ & $93.44(1.05)$ & 0.904 \\
\hline Mean $\mathrm{FEV}_{1} \mathrm{z}$-score (SEM) & $-0.45(0.05)$ & $-0.48(0.09)$ & 0.797 \\
\hline Mean FVC \% predicted (SEM) & $98.36(0.69)$ & $97.84(1.00)$ & 0.694 \\
\hline Mean FVC z-score (SEM) & $-0.06(0.05)$ & $-0.13(0.08)$ & 0.462 \\
\hline Mean $\mathrm{FEV}_{1} / \mathrm{FVC}$ (SEM) & $83.75(0.37)$ & $84.29(0.57)$ & 0.451 \\
\hline $\mathrm{FEV}_{1} / \mathrm{FVC}$ z-score (SEM) & $-0.70(0.05)$ & $-0.66(0.08)$ & 0.701 \\
\hline Median FeNO in ppb (IQR) & $25(12-54)$ & $16(9-37)$ & $0.004^{*}$ \\
\hline
\end{tabular}

Reversibility testing using salbutamol was performed in all children with $\mathrm{FEV}_{1}<80 \%$ predicted or $\mathrm{FEV}_{1} / \mathrm{FVC}<80 \%$ on baseline spirometry. Of the 172 children meeting this criterion, $56(32.6 \%)$ demonstrated an increase in $\mathrm{FEV}_{1}$ (L) of $\geq 12 \%$ postbronchodilation.

\section{Fraction of exhaled nitric oxide}

FeNO results were obtained from $472(77.1 \%)$ children. FeNO $\geq 35 \mathrm{ppb}$ was identified in 171 children (36\%) ranging from 36 to $231 \mathrm{ppb}$. The median (IQR) FeNO for children on the asthma register was higher; $25(12-54)$ vs 16 (9-37), median difference $=-5.0,95 \%$ CI $(-9.0$ to 2.0$), \mathrm{p}=0.004$.

Four hundred and sixty-five (76\%) children were able to perform both spirometry and FeNO testing (figure 1). Only half had normal results for both tests, $n=240(52 \%)$.

\section{Current asthma symptom control}

Among our cohort, 256 children (41.8\%) had poor current asthma symptom control according to their ACT/CACT test scores. One hundred ninety-seven out of 456 (43.2\%) on the asthma register and 59 out of $156(37.8 \%)$ not on their GP asthma register had ACT/CACT scores $\leq 19(\mathrm{p}=0.24)$.

Table 2 Number of abnormal spirometry results by definition used

\begin{tabular}{llc}
\hline Abnormality & Definition used & Number \\
\hline Obstruction & $\mathrm{FEV}_{1}$ or $\mathrm{FEV}_{1} / \mathrm{FVC}<\mathrm{LLN}$ & $135(23.5 \%)$ \\
& $\mathrm{FEV}_{1} \%$ predicted $<80$ or $\mathrm{FEV}_{1} / \mathrm{FVC}<80 \%$ & $172(29.9 \%)$ \\
& $\mathrm{FEV}_{1} / \mathrm{FVC}<70 \%$ & $27(4.7 \%)$ \\
\multirow{2}{*}{ Restriction } & Isolated $\mathrm{FVC}$ predicted $<80 \%$ & $5(0.9 \%)$ \\
& Isolated $\mathrm{FVC}<\mathrm{LLN}$ & $4(0.7 \%)$ \\
\hline
\end{tabular}

LLN, lower limits of normal. 


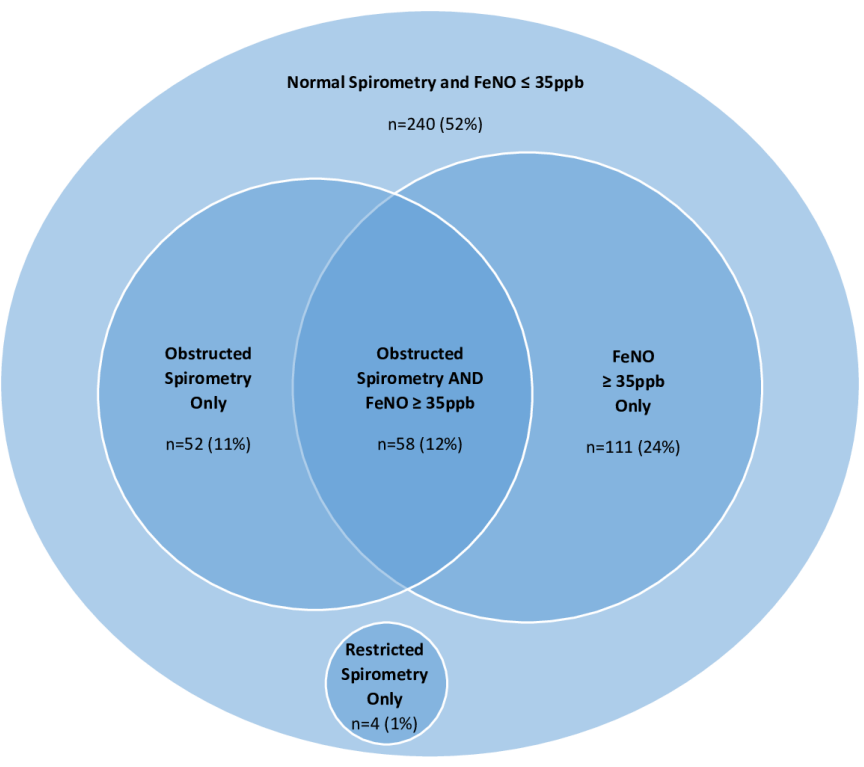

Figure 1 Number (percentage) of children with each combination of test results, based only on children who were able to perform both tests satisfactorily. Obstructed spirometry defined as $\mathrm{FEV}_{1}$ or $\mathrm{FEV}_{1} / \mathrm{FVC}<\mathrm{LLN}$ using GLI reference values. Restricted spirometry defined as FVC $<\mathrm{LLN}$. GLI, global lung initiative; FeNO, fraction of exhaled nitric oxide; LLN, lower limits of normal; ppb, parts per billion.

\section{Relationship between spirometry, FeNO and current asthma symptom control}

Children with current uncontrolled asthma (CACT/ACT $\leq 19$ ) were more likely to have obstructed spirometry compared with those with good current control (CACT/ACT >19); $28.5 \%$ vs $20.2 \%(\mathrm{p}=0.022)$. Although both $\mathrm{FEV}_{1} \mathrm{z}$-scores $(\mathrm{r}=0.172 ; 95 \%$ CI 0.037 to 0.302 ) and $\mathrm{FEV}_{1} / \mathrm{FVC}$ z-scores $(\mathrm{r}=0.238$; $95 \% \mathrm{CI}$ 0.105 to 0.362 ) correlated weakly with ACT scores (children 12-16 years), the correlation coefficients were low, with a wide spread of data. In younger children (5-11 years), while there was also a weak trend towards higher values for $\mathrm{FEV}_{1}$ and $\mathrm{FEV}_{1} /$ FVC with higher CACT scores, these did not reach significance (figure 2).
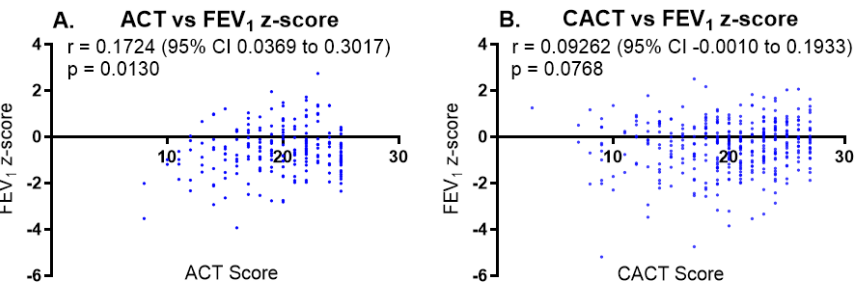

C. ACT vs FEV 1 /FVC z-score
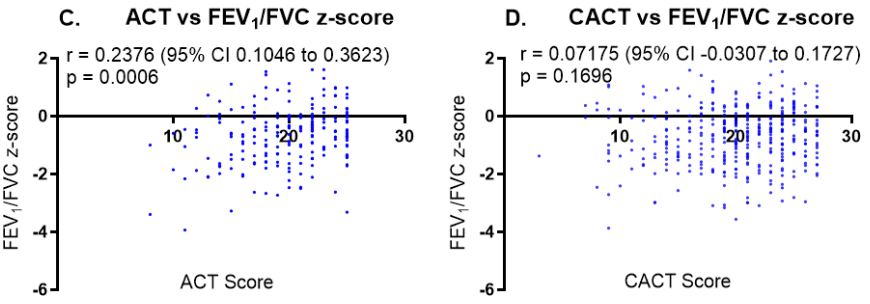

Figure 2 (A-D) Scatter plots showing the relationships between spirometric parameters and asthma control as measured using the asthma control test (ACT) for children 12 years and over, and the childhood asthma control test (CACT) for those aged 5-11 years. The correlation coefficient $(r), \mathrm{Cl}$ values and $\mathrm{p}$ values are shown.
Table 3 Number of children with each combination of results according to reported current asthma symptom control

\begin{tabular}{llll}
\hline & $\begin{array}{c}\text { Obstructed } \\
\text { spirometry }\end{array}$ & Normal spirometry & $\begin{array}{c}\text { Restricted } \\
\text { spirometry }\end{array}$ \\
\hline Poor control (ACT/CACT $\leq 19), \mathrm{n}=191$ & & \\
\hline FeNO $\geq 35$ & $25(13 \%)$ & $46(24 \%)$ & 0 \\
\hline FeNO $<35$ & $25(13 \%)$ & $93(49 \%)$ & $2(1 \%)$ \\
\hline Good control (ACT/CACT $>19), n=274$ & & \\
\hline FeNO $\geq 35$ & $33(12 \%)$ & $65(24 \%)$ & 0 \\
\hline FeNO $<35$ & $27(10 \%)$ & $147(54 \%)$ & $2(1 \%)$ \\
\hline
\end{tabular}

Obstructed spirometry defined as $\mathrm{FEV}_{1}$ or $\mathrm{FEV}_{1} / \mathrm{FVC}<\mathrm{LLN}$ using $\mathrm{GLI}$ reference values. Normal spirometry defined as $\mathrm{FEV}_{1}$ and $F E V_{1} / F V C \geq L L N$. Restricted spirometry defined as FVC $<$ LLN.

$\mathrm{ACT}$, asthma control test; $\mathrm{CACT}$, childhood asthma control test; FeNO, fraction of exhaled nitric oxide.

There was no difference in the percentage of children with FeNO $\geq 35$ ppb between those with good or poor current asthma symptom control.

In children where both spirometry and FeNO data were available (table 3), 46\% of children reporting good current control (ACT/CACT score >19) had at least one objective test abnormality. By contrast, in those reporting poor current control, 93 out of 191 (49\%) children had normal spirometry and FeNO.

In terms of UHAs, children with poor current asthma control (ACT/CACT $\leq 19)$ and obstructed lung function (GLI LLN) had almost double the mean (SEM) number of UHAs in the 6 months prior to review compared with children with poor current control but normal spirometry; $0.58(0.11)$ vs 0.31 (0.05), mean difference $=-0.27,95 \% \mathrm{CI}(-0.07$ to 0.47$), \mathrm{p}=0.036$. There was no difference in the mean (SEM) number of UHAs in children with poor current control and raised $\mathrm{FeNO}$ versus children with poor current control and normal FeNO; 0.42 (0.09) vs 0.42 (0.07), mean difference $=-0.001,95 \%$ CI $(-0.23$ to 0.23$), p=0.861$.

\section{Potential role of spirometry and FeNO in asthma diagnosis}

Spirometry and FeNO data were available from 109 children who had received asthma medications in the previous year, but who were not on the asthma register. Of these, $12 \%$ had obstructed spirometry (GLI LLN) and BDR $\geq 12 \%$ to salbutamol and could have asthma confirmed according to NICE guidance. A further $6 \%$ had obstructed spirometry and FeNO $\geq 35$ ppb, 11\% had obstructed spirometry only, and 13\% had raised FeNO only; these children would warrant further investigation. Normal spirometry and FeNO was found in 58\% of children not on the asthma register.

\section{Follow-up}

Unplanned healthcare attendances

Electronic records were reviewed for $605 / 612$ children 6 months post asthma review. Seven children had moved GP surgery so their records were no longer accessible. The mean (SEM) number of UHAs fell from $0.31(0.03)$ per child in the 6 months preceding review to $0.20(0.02)$ per child over the 6 months following review; mean difference $=-0.11,95 \%$ CI $(-0.05$ to $0.17), \mathrm{p}=0.0004$.

The number of children with at least one UHA also fell from 140 out of $612(23 \%)$ children to 100 out of $605(16.5 \%)$ children at follow-up, representing a relative reduction of $28 \%$. 


\section{Current asthma symptom control}

Follow-up asthma control tests were returned by 226 (37\%) children. Overall, median (IQR) ACT scores improved from 20 $(17-23)$ to 22 (19-24), median difference $=-1.0,95 \% \mathrm{CI}(-2.5$ to 0.0$), \mathrm{p}=0.032$, and CACT from $21(19-24)$ to $23(19.5-25)$, median difference $=-1.5,95 \%$ CI $(-2.0$ to 0.5$), \mathrm{p}<0.0001$ in the 6 months following review.

\section{DISCUSSION}

We conducted a large study in primary care to explore the feasibility of spirometry and FeNO testing for the management of children's asthma. Abnormal spirometry was identified in almost one-quarter of children studied. Although comparison of prevalence of abnormal spirometry with other studies is not straightforward, due to different criteria for normality and reference equations used, our finding is broadly similar to two North American studies involving children with asthma. ${ }^{15} 16$ Previous studies have shown that children with an $\mathrm{FEV}_{1}$ of $60 \%-80 \%$ predicted are 1.4-1.8 times more likely to experience an asthma attack over the subsequent year. ${ }^{1718}$

FeNO levels $\geq 35$ ppb were identified in $36 \%$ of our cohort. This has potential implications for predicting the risk of future loss of asthma control, ${ }^{19}$ and FeNO-guided asthma management may have a role in reducing asthma attacks. ${ }^{6}$

Given the association between abnormal spirometry and FeNO with poor asthma outcomes, the high prevalence of abnormal lung function and $\mathrm{FeNO}$ seen in our cohort highlights the need for objective measurements in asthma monitoring to fully appreciate the future risk of adverse asthma events.

In children able to perform both spirometry and $\mathrm{FeNO}$ testing, around half had at least one abnormal test result. Of those with at least one abnormality, approximately half had raised FeNO alone, one-quarter had obstructed spirometry alone and onequarter had abnormal results for both, suggesting a complementary role for both FeNO and spirometry in children's asthma monitoring.

We found a statistically significant, but weak relationship between ACT scores with $\mathrm{FEV}_{1}$ and $\mathrm{FEV}_{1} / \mathrm{FVC}$, and no correlation between CACT scores with either $\mathrm{FEV}_{1}$ or $\mathrm{FEV}_{1} / \mathrm{FVC}$. There was also no correlation between FeNO with either ACT or CACT scores. Recent studies have similarly reported weak correlations between spirometry and ACT in adults, ${ }^{20}$ but not between spirometry or FeNO and CACT in younger children. ${ }^{21}$ This might reflect a disassociation between a patient's asthma symptoms and their perception of those symptoms, ${ }^{22}{ }^{23}$ or a temporal delay between changes in symptoms and lung function. $^{2425}$

Importantly, almost half the children in our cohort reporting good current asthma control had at least one objective test abnormality; with $12 \%$ having both abnormal spirometry and FeNO. This suggests that asthma severity ${ }^{26}$ and suboptimal control ${ }^{2}$ may be under-recognised when clinical evaluation is based on symptoms alone. By contrast, $49 \%$ of children reporting poor current control had normal tests, suggesting either incorrect asthma diagnosis, or highlighting that children can be symptomatic despite normal lung function. Similarly, a US study involving 201 children found that asthma assessments based on history alone underestimated asthma severity determined by spirometry in $31 \%$ of children, while assessments using spirometry alone under-recognised poor control in $40 \%$ of symptomatic children compared with clinician-determined severity. ${ }^{27}$ Although this study predates publication of GLI reference values, making direct comparison with our data challenging, it highlights the fact that asthma assessments based on either symptoms, or objective tests in isolation do not provide a full picture of the child with asthma.

Under-recognition of the underlying severity of a child's asthma has potentially severe consequences. Two recent coroners' reports in the UK, both identified failures in the management of two children who died in 2014 and 2015, emphasising the lack of appreciation and recognition of the severity of their condition and the deteriorating nature of their clinical control (Carney 2015; Radcliffe 2017). We believe this highlights the need for objective measures of asthma control in addition to the traditional symptoms-based approach.

Around a quarter of our cohort had at least one UHA in the 6 months preceding review. This is higher than previously reported asthma attack rates in children of $8 \%-36 \%$ per year ${ }^{28} 29$ and may be due to different definitions for asthma attacks. Previous UK studies ${ }^{28}{ }^{30}$ defined attacks as ED attendances or the need for oral corticosteroids (OCS); these criteria may have missed milder attacks where no OCS were prescribed. We included any asthma-related UHA regardless of OCS prescription where children received increased inhaled or nebulised short-acting bronchodilators, and referred to discharge letters stored as text documents even if they were not coded electronically. The recent Lancet commission on asthma ${ }^{31}$ discusses the heterogeneity of asthma attacks at all ages and emphasises that any loss of symptom control should be taken seriously.

In children reporting poor current asthma control, we found those with obstructed airflow had almost double the mean number of UHAs at baseline compared with children with normal lung function. This association has potentially important implications for asthma attack risk stratification.

Notably, following an asthma review that included objective tests, we observed a small improvement in ACT/CACT scores during follow-up. This is arguably subjective and possibly a result of study (Hawthorne) effect. ${ }^{32}$ Moreover, the improvement in asthma control test scores at follow-up were below the published minimally clinically important change in scores for both ACT and CACT of 3-points and 2-points, respectively.

However, the mean number of UHAs and the proportion of children having at least one UHA also fell by almost a third. We speculate that this resulted from practice nurses being trained as part of this study to act on both patient-reported symptoms and objective evidence from spirometry and FeNO, leading to an increased recognition of suboptimal control, undertreatment or poor compliance with preventer medications and more accurate titration of asthma treatment. This requires confirmation in an adequately powered clinical trial. Previous studies have similarly demonstrated that asthma reviews conducted by trained asthma nurses in primary care can improve patient outcomes and reduce asthma attacks ${ }^{33}{ }^{34}$; however, these studies did not include the use of spirometry or FeNO as part of the asthma review.

Previous asthma studies comparing standard symptoms-based monitoring versus monitoring with additional spirometry or FeNO have not found significant differences between groups in terms of reported symptoms. There is, however, some evidence that children monitored with FeNO may have fewer asthma attacks. ${ }^{63536}$

An Australian trial comparing standard asthma monitoring versus active monitoring with spirometry reported no difference in number of asthma attacks. ${ }^{37}$ This trial did not however, include a management algorithm to direct treatment of children with abnormal lung function. Intuitively, spirometry-based monitoring would only be effective if abnormal results are acted on appropriately. 
In terms of diagnosis, one-quarter of our cohort were identified based on them receiving asthma medications in the previous year despite not having a coded asthma diagnosis. We believe this may reflect both a hesitance to formally diagnose children with asthma in primary care, and an issue with coding practices, that is, the child is diagnosed but this is not recorded on the practice database. These children would not automatically be recalled for a routine annual asthma review and are at risk of having unrecognised poor symptom control. Using the NICE asthma diagnosis algorithm, $12 \%$ of our cohort without an existing asthma diagnosis had asthma confirmed, and a further $6 \%$ had probable asthma based on two positive tests, demonstrating the potential usefulness of providing objective tests within primary care. This is similar to the findings of the NICE asthma guideline feasibility study (NICE 2017), which were able to confirm an asthma diagnosis in $24.5 \%$ of their cohort, who presented acutely with asthma symptoms. As both lung function and FeNO can fluctuate, it is possible that our diagnosis rate was slightly lower, due to our cohort of children being recruited during routine reviews and not when they were presenting acutely unwell.

Strengths: we prospectively recruited a large cohort of children from practices representative of different ethno-socioeconomic populations. All but two children attending the asthma review participated. As follow-up data were collected primarily from electronic records, only seven (1\%) children were lost to follow-up; in remaining children, datasets were complete for baseline and follow-up UHAs, making our data robust. All training for spirometry and $\mathrm{FeNO}$ were delivered by the same study team members; and every spirogram was reviewed for acceptability following ATS/ERS recommendations to ensure quality of lung function data.

Limitations: the absence of a control arm makes the interpretation of the apparent fall in asthma attacks seen in our cohort difficult. As attendance was voluntary, it is possible that only more symptomatic children attended; biassing our cohort towards those with poorer current asthma symptom control and poorer lung function. Second, practice staff were trained to interpret spirometry using fixed cut-offs rather than GLI LLN, despite the latter being the gold standard. This was a conscious decision by the study team for pragmatic reasons, as practice staff were already familiar with the use of fixed cut-offs in the context of performing adult spirometry. As routine spirometry becomes accepted in general practice, we recommend that fixed cut-offs should be superseded by LLN.

Also, asthma is a chronic relapsing condition and this study has included clinical assessments at one point in time only; therefore, our findings and conclusions relate to that one snapshot and may not accurately reflect longitudinal asthma control. Additionally, we did not set out to control for the effect of seasonality on symptom control and asthma attacks, however we recruited our patients over a 14-month period across all four seasons, making a seasonal influence on our data unlikely

Finally, all participating practices were from the same, although diverse, geographical region within the East Midlands, UK; it is possible that only the most motivated practices expressed an interest to participate, resulting in a group of practices which may not be representative.

To our knowledge, this is the first primary care study in the UK to explore the role of spirometry and FeNO testing in monitoring children with asthma. We have shown that abnormal lung function and FeNO are highly prevalent in children who attend for asthma reviews in primary care, and correlates poorly with patient-reported symptom scores. Symptomatic children with abnormal lung function were also more likely to have had an asthma attack during the study period. Moreover, we observed a reduction in the number of asthma attacks and improved current asthma control test scores in the 6 months after the clinical review which included objective tests. This important observation requires confirmation with an adequately powered randomised clinical trial, with repeat objective testing over time, in order to demonstrate causation and longitudinal changes in lung function. To conclude, our data suggests that a symptomsbased assessment alone is inadequate, and is likely to miss children at high risk of a near future severe asthma attack.

\section{Author affiliations}

${ }^{1}$ Department of Respiratory Sciences. Leicester NIHR Biomedical Research Centre (Respiratory theme), University of Leicester College of Life Sciences, Leicester, UK ${ }^{2}$ Paediatric Respiratory Medicine, University Hospitals of Leicester NHS Trust, Leicester, UK

${ }^{3}$ Department of Respiratory Sciences. Leicester NIHR Biomedical Research Centre (Respiratory theme), University of Leicester, Leicester, UK

${ }^{4}$ SAPPHIRE Group, Health Sciences, University of Leicester, Leicester, UK

${ }^{5}$ Paediatric Emergency Medicine Leicester Academic (PEMLA) Group, Children's

Emergency Department, Leicester Royal Infirmary, Leicester, UK

${ }^{6}$ Leicester NIHR Biomedical Research Centre, National Institute for Health Research, Leicester, UK

${ }^{7}$ Department of Respiratory Sciences, University of Leicester College of Life Sciences, Leicester, UK

${ }^{8}$ Nuffield Department of Primary Care Health Sciences, University of Oxford, Oxford, UK

${ }^{9}$ Health Sciences, University of Leicester, Leicester, UK

\section{Twitter David KH Lo @David_Lo}

Acknowledgements The authors would like to thank the staff, children and families at all participating general practices for their support of this study.

Contributors EAG, DL, CB, DR, MR, YY and AW participated in the initial design of the study. DL and LD were responsible for data collection and providing training to the general practices. DL was responsible for data analyses and initial manuscript preparation with input from EAG and CB. Statistical input was provided by MR. All coauthors contributed to the interpretation of results, and provided revisions and approval of the final manuscript. YY was supported by the Oxford NIHR Biomedical Research Centre duing this study.

Funding This study was funded from grants provided by the Midlands Asthma and Allergy Research Association (MAARA) and Circassia Pharmaceuticals to EAG. DL was funded by Health Education East Midlands.

Competing interests EAG: consultancy work for Boehringer Ingelheim in November 2016 and Anaxsys in July 2018 with money paid to the institution (University of Leicester), Investigator-led research grant from Circassia and Gilead. Research collaboration with Medimmune. Travel grants from Vertex. YY: was supported by the Oxford NIHR Biomedical Research Centre during this study.

Patient consent for publication Not required.

Ethics approval Ethics approval was obtained from the NHS Research Ethics Committee (16/EM/0162).

Provenance and peer review Not commissioned; externally peer reviewed.

Data availability statement Data are available on reasonable request.

\section{ORCID iD}

David KH Lo http://orcid.org/0000-0002-3220-7159

\section{REFERENCES}

1. Shah R, Hagell A, Cheung R. International comparisons of health and wellbeing in adolescence and early adulthood. London, UK: Nuffield Trust, 2019.

2. BTS. British Thoracic Society and Scottish Intercollegiate Network Guideline on the Management of Asthma, 2016.

3. RCP. Why asthma still kills? The National review of asthma deaths, 2014

4. GINA. Global initiative for asthma pocket guide for asthma management and prevention for adults and children older than 5 years, 2017.

5. NICE. The National Institute for health and care excellence (NICE). guideline for asthma: diagnosis, monitoring and chronic asthma management, 2017. Available: https://www.nice.org.uk/guidance/ng80 [Accessed 2019].

6. Petsky HL, Kew KM, Chang AB, et al. Exhaled nitric oxide levels to guide treatment for children with asthma. Cochrane Database Syst Rev 2016;179.

7. NICE. Asthma (including children and young people): diagnosis and monitoring: Stakeholder workshop, 2013. 
8. Nash S. Bma wholly rejects NICE recommendations on asthma in scathing response, 2015. Available: http://www.pulsetoday.co.uk/clinical/respiratory-/bma-whollyrejects-nice-recommendations-on-asthma-in-scathing-response/20010520.article\#. VavfrYsijdk

9. Price C. NICE chiefs forced to re-consult on asthma diagnosis plans, 2017. Available: http://www.pulsetoday.co.uk/clinical/more-clinical-areas/respiratory-/nice-chiefsforced-to-re-consult-on-asthma-diagnosis-plans/20034091.article

10. Nathan RA, Sorkness CA, Kosinski M, et al. Development of the asthma control test: a survey for assessing asthma control. J Allergy Clin Immunol 2004;113:59-65.

11. Liu AH, Zeiger R, Sorkness $C$, et al. Development and cross-sectional validation of the childhood asthma control test. J Allergy Clin Immunol 2007;119:817-25.

12. Miller MR, Hankinson J, Brusasco V, et al. Standardisation of spirometry. Eur Respir J 2005;26:319-38.

13. Quanjer PH, Stanojevic S, Cole TJ, et al. Multi-Ethnic reference values for spirometry for the 3-95-yr age range: the global lung function 2012 equations. Eur Respir J 2012;40:1324-43.

14. American Thoracic Society, European Respiratory Society. ATS/ERS recommendations for standardized procedures for the online and offline measurement of exhaled lower respiratory nitric oxide and nasal nitric oxide, 2005. Am J Respir Crit Care Med 2005; 171:912-30.

15. Bacharier LB, Strunk RC, Mauger D, et al. Classifying asthma severity in children: mismatch between symptoms, medication use, and lung function. Am J Respir Crit Care Med 2004;170:426-32.

16. Galant SP, Morphew T, Newcomb RL, et al. The relationship of the bronchodilator response phenotype to poor asthma control in children with normal spirometry. $J$ Pediatr 2011;158:953-9.

17. Fuhlbrigge $A L$, Kitch $B T$, Paltiel $A D$, et al. $F E V(1)$ is associated with risk of asthma attacks in a pediatric population. J Allergy Clin Immunol 2001;107:61-7.

18. Fuhlbrigge AL, Weiss ST, Kuntz KM, et al. Forced expiratory volume in 1 second percentage improves the classification of severity among children with asthma. Pediatrics 2006;118:e347-55

19. Yang S, Park J, Lee YK, et al. Association of longitudinal fractional exhaled nitric oxide measurements with asthma control in atopic children. Respir Med 2015;109:572-9.

20. Papakosta D, Latsios D, Manika K, et al. Asthma Control Test Is Correlated to FEV , and Nitric Oxide in Greek Asthmatic Patients: Influence of Treatment. J Asthma 2011:48:901-6.

21. Green RJ, Klein M, Becker $P$, et al. Disagreement among common measures of asthma control in children. Chest 2013;143:117-22.
22. Rietveld S, Everaerd W, Walter E. Perceptions of asthma by adolescents at home. Chest 2000;117:434-9.

23. Mammen JR, Rhee $H$, Norton SA, et al. Perceptions and experiences underlying self-management and reporting of symptoms in teens with asthma. J Asthma 2017;54:143-52.

24. Anandi S, Tullu MS, Lahiri K. Evaluation of symptoms \& spirometry in children treated for asthma. Indian J Med Res 2016;144:124-7.

25. Mehta V, Stokes JR, Berro A, et al. Time-Dependent effects of inhaled corticosteroids on lung function, bronchial hyperresponsiveness, and airway inflammation in asthma. Annals of Allergy, Asthma \& Immunology 2009;103:31-7.

26. NAEPP. National asthma education and prevention programme. Guidelines for the diagnosis and management of asthma, 2007.

27. Cowen MK, Wakefield DB, Cloutier MM. Classifying asthma severity: objective versus subjective measures. J Asthma 2007;44:711-5.

28. Suruki RY, Daugherty JB, Boudiaf N, et al. The frequency of asthma exacerbations and healthcare utilization in patients with asthma from the UK and USA. BMC Pulm Med 2017;17:74.

29. Rabe KF, Vermeire PA, Soriano JB, et al. Clinical management of asthma in 1999: the asthma insights and reality in Europe (AIRE) study. Eur Respir J 2000;16:802-7.

30. Bloom Cl, Nissen F, Douglas IJ, et al. Exacerbation risk and characterisation of the UK's asthma population from infants to old age. Thorax 2018;73:313-20.

31. Pavord ID, Beasley R, Agusti A, et al. After asthma: redefining airways diseases. The Lancet 2018;391:350-400.

32. McCambridge J, Witton J, Elbourne DR. Systematic review of the Hawthorne effect: new concepts are needed to study research participation effects. J Clin Epidemiol 2014;67:267-77

33. Cave AJ, Wright A, Dorrett J, et al. Evaluation of a Nurse-run asthma clinic in general practice. Prim Care Respir J 2001:10:65-8.

34. Griffiths C, Foster G, Barnes N, et al. Specialist nurse intervention to reduce unscheduled asthma care in a deprived multiethnic area: the East London randomised controlled trial for high risk asthma (ELECTRA). BMJ 2004;328.

35. Gomersal T, Harnan S, Essat M, et al. A systematic review of fractional exhaled nitric oxide in the routine management of childhood asthma. Pediatr Pulmonol 2016;51:316-28.

36. Lu M, Wu B, Che D, et al. FeNO and asthma treatment in children: a systematic review and meta-analysis. Medicine 2015;94:e347.

37 Abramson MJ, Schattner RL, Holton C, et al. Spirometry and regular follow-up do not improve quality of life in children or adolescents with asthma: cluster randomized controlled trials. Pediatr Pulmonol 2015:50:947-54. 